\title{
Mechanism of the Greenland-Scotland Ridge overflow variation under different atmospheric $\mathrm{CO}_{2}$ scenarios
}

\author{
MU Lin ${ }^{1, *}$, SONG Jun ${ }^{1}$, ZHONG LinHao ${ }^{2}$, WANG LanNing ${ }^{3}$, LI Huan ${ }^{1} \&$ LI Yan ${ }^{1}$ \\ ${ }^{1}$ National Marine Data and Information Service, Tianjin 300171, China; \\ ${ }^{2}$ Institute of Atmospheric Physics, Chinese Academy of Sciences, Beijing 100029, China; \\ ${ }^{3}$ Beijing Normal University, Beijing 100875, China; \\ ${ }^{4}$ Max-Planck Institute for Meteorology, Hamburg 20146, Germany
}

Received March 25, 2011; accepted May 30, 2011

\begin{abstract}
Baroclinic transport and the barotropic effect are two different viewpoints for understanding the mechanism of the GreenlandScotland Ridge overflow. The mechanism of this overflow, being an important deep branch of thermohaline circulation, deserves research discussion, especially against the background of global warming. Using the newly developed ECHAM5/MPI-OM, of the Max Planck Institute for Meteorology, which is an advanced atmosphere-sea ice-ocean coupled climate model, the mechanism of the Greenland-Scotland Ridge overflow variation under different atmospheric $\mathrm{CO}_{2}$ scenarios is studied. First, a control experiment is forced by a fixed $\mathrm{CO}_{2}$ concentration of $280 \mathrm{ppmv}$, which is the pre-industrial level before 1860. Three sensitive experiments are carried out under different scenarios of increased atmospheric $\mathrm{CO}_{2}$ concentrations, which are listed in the Intergovernmental Panel on Climate Change (IPCC) assessment report (B1, A1B and A2). In the control run, more water with higher salinity intruding into the Greenland-Icelandic-Norwegian Seas results in greater barotropic transport and greater overflow because of the baroclinic effect. Therefore, the barotropic effect and baroclinic effect on the overflow are unified. Under the atmospheric $\mathrm{CO}_{2}$ scenarios, the strength of overflow across the Faro-Bank Channel is controlled by the baroclinic effect and the increase in Denmark Strait overflow is attributed to the barotropic effect.
\end{abstract}

Greenland-Scotland Ridge overflow, $\mathrm{CO}_{2}$, global warming, dynamic mechanism, numerical model

Citation: $\quad \mathrm{Mu} \mathrm{L}$, Song J, Zhong L H, et al. Mechanism of the Greenland-Scotland Ridge overflow variation under different atmospheric $\mathrm{CO}_{2}$ scenarios. $_{\text {Chinese Sci }}$ Bull, 2011, 56: 2635-2643, doi: 10.1007/s11434-011-4601-1

The Greenland-Scotland Ridge, located on the northern edge of the Atlantic Ocean basin and connecting the Greenland-Iceland-Norway (GIN) Seas and the North Atlantic Ocean basin, comprises the Denmark Strait and the FaroBank Channel (Figure 1).

The southern side of the Greenland-Scotland Ridge has an average depth of $600 \mathrm{~m}$, with the northern side being deeper than $3700 \mathrm{~m}$. This steep benthal topography rapidly decreases the high-density overflow across the Denmark Strait and the Faro-Bank Channel, resulting in the wellknown benthal falls. The North Atlantic Current intrudes into the GIN Seas via surface current crossing the Faro-

\footnotetext{
*Corresponding author (email: moulin1977@ hotmail.com)
}

Bank Channel. Some of the water becomes deep water via deep convection and flows out of the GIN Seas in the form of Greenland-Scotland Ridge overflow, while the remainder remains as surface current and flows out of the GIN Seas, crossing the Denmark Strait and the Faro-Bank Channel [1].

The Greenland-Scotland Ridge overflow has two parts: overflow across the Denmark Strait and overflow across the Faro-Bank Channel. The Greenland-Scotland Ridge overflow is the main body of the North Atlantic Deep Water (NADW) and the most important deep circulation branch of thermohaline circulation (THC) [2]. The overflow greatly affects the strength of THC [3] and the THC plays a major role in meridional heat transport in the Atlantic (Figure 1).

Human-induced global warming due to increased levels 


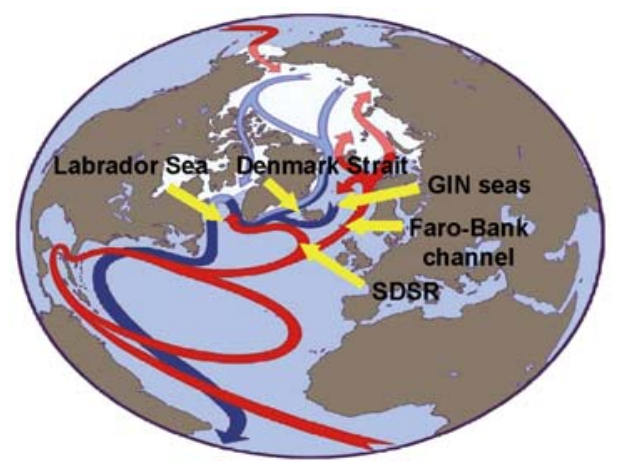

Figure 1 Schematic diagram of North Atlantic circulation (surface light seawater and deep heavy seawater are shown by red lines and blue lines respectively).

of atmospheric $\mathrm{CO}_{2}$ and other greenhouse gases can affect the Earth's climate system. In this process, the change in THC is especially remarkable [4]. The mechanism of the Greenland-Scotland Ridge overflow, as an important deep circulation branch of THC, deserves research.

There are two viewpoints regarding the mechanism. Classical theories [5,6] attribute the overflow to convection in the deep water of the GIN seas. In this case, the strength of the overflow depends on the intensity of the deep convection. Employing hydrodynamic theory and a relevant two-layer model, Whitehead [7] concluded that the strength of the overflow is determined by the density difference across the ridge and the effective dynamic height. When deep convection in the GIN Seas strengthens, the isopycnal upwarps, the deep-water density increases, and there is a large density difference across the sea ridge and a high effective dynamic height. Finally, the overflow strengthens.

The second viewpoint is that of Mauritzen, and is based on basic physical concepts [8,9]. By analyzing observation data recorded over a long period, she concluded that the strength of the overflow is determined by the strength of the inflow crossing the Faro-Bank Channel. Therefore, the barotropic effect, not the baroclinic transport, would play a major role in the Greenland-Scotland Ridge overflow.

The mechanism of the Greenland-Scotland Ridge overflow thus requires further study [10-12]. On the basis of the ECHAM5/MPI-OM climate model of the Max Planck Institute for Meteorology, the mechanism of the Greenland-Scotland Ridge overflow under different atmospheric $\mathrm{CO}_{2}$ scenarios is discussed in this article.

\section{Numerical model and numerical experiments}

\subsection{Model configuration}

The meteorological global atmosphere-ocean-sea-ice model of the Max Planck Institute named ECHAM5/MPI-OM is used in our study. The Max Planck Institute Ocean Model (MPI-OM) is a global general ocean circulation model based on an orthogonal curvilinear Arakawa C-grid, which contains a free surface and a state-of-the-art sea ice model with viscous-plastic rheology and snow. The Max Planck Institute Atmosphere Model (ECHAM) was derived from global forecast models developed at the European Centre for Medium-Range Weather Forecasts.

There is no flux adjustment in ECHAM5/MPI-OM, which is an important advantage of this coupled model. ECHAM5 is a modification of the extensively used ECHAM4 in which the aerosol module has been improved and the cloud-cover parameterization updated. Additionally, water and ice in the cloud are treated separately, which improves the simulation of precipitation. A new set of land surface data (vegetation ratio, leaf area index and forest ratio) are employed in ECHAM5 [13]. The changes in MPI$\mathrm{OM}$ are improvement of the sea surface-wind stress calculation by considering the influence of local current to depict the ocean upper-layer dynamics more accurately. Meanwhile, the modified sea-ice module describes the growing, melting and transport of sea ice more exactly [14].

An orthogonal curvilinear grid allows for an arbitrary placement of the grid poles [14]. In the current setup, the model's North Pole is shifted to Greenland and the South Pole is at the center of the Antarctic continent. This approach not only removes the numerical singularity associated with the convergence of meridians at the geographical North Pole but also produces higher resolution in the regions of NADW formation near Greenland (Greenland Sea, Labrador Sea). The grid spacing is a minimum of about 15 $\mathrm{km}$ around Greenland and a maximum of $184 \mathrm{~km}$ in the Pacific. The ocean has a $1.5^{\circ}$ average horizontal grid spacing with 40 vertical levels, which are spaced unevenly.

The ECHAM has been modified for climate research and the current version is ECHAM5. The atmospheric model uses ECHAM version 5.2 and is run at T63 resolution $\left(1.875^{\circ} \times 1.875^{\circ}\right)$ with 31 vertical (hybrid) levels [13]. The topography is taken from ETOPO-5 data (www.ngdc.noaa. gov/mgg/global/relief/ETOP05) [15].

\subsection{Numerical experimentation}

On the basis of the fourth evaluation report of the Intergovernmental Panel on Climate Change (IPCC) (http://ipccwg1.ucar.edu/wg1/wg1-report.html), the model is run using the $\mathrm{CO}_{2}$ scenario of $280 \mathrm{ppmv}$, the pre-industrial level before 1860 . The adjustment of the ocean is slower than that of the atmosphere. Therefore, we first run the ocean model only and do not start the coupled model until the ocean model reaches a state of equilibrium. Finally, we let the coupled model reach a state of equilibrium.

The numerical simulation spins up for 500 years. The simulation for validation is then forced by the $\mathrm{CO}_{2}$ concentration, which is taken from observation and reanalysis data for the period from 1860 to 2000 .

The coupled model is run under different increased atmospheric $\mathrm{CO}_{2}$ scenarios, which are among the scenarios 
listed in the IPCC report (Figure 2). From 1860 to 2000 in the numerical simulation, the observation value is used as the $\mathrm{CO}_{2}$ forcing. From 2000, the coupled model is run under three scenarios of the IPCC (B1, A1B and A2). The A2 scenario assumes a future world in which the global economy develops rapidly, the global population grows quickly, new energy resources and technologies are not used, and $\mathrm{CO}_{2}$ concentrations increase rapidly. In the A1B scenario, the global population and economy develop quickly, and a balanced strategy for fuel use is adopted, where "balanced" means not relying too heavily on one particular energy resource, under the assumption that similar improvement rates apply to all energy supplies and terminal technologies. In the B1 scenario, the global population peaks in the middle of the 21 st century and declines thereafter, there is rapid change in economic structures toward a service and information economy with less use of materials, and clean and efficient technologies are used. In this optimistic scenario, the $\mathrm{CO}_{2}$ concentration will increase slowly and then stabilize.

Employing the above numerical experiment design, we run the coupled model under different scenarios of increasing levels of greenhouse gases on the super computer of the German Climate Center. Firstly, the coupled model spins up for 500 years under a fixed $\mathrm{CO}_{2}$ concentration of $280 \mathrm{ppmv}$, which is the $\mathrm{CO}_{2}$ concentration before industrialization. Secondly, the coupled model is run from 1860 to 2000 under the observed $\mathrm{CO}_{2}$ concentration. Finally, the model is driven under the $\mathrm{B} 1, \mathrm{~A} 1 \mathrm{~B}$ and $\mathrm{A} 2$ scenarios after 2000 . Because the computation is time-consuming in these cases, only one test is run for each scenario. The output result is monthly mean values. The results for the control run and A1B are discussed in this article.

\subsection{Analytical method}

This paper divides the Atlantic Ocean into three density classes to analyze the output of the coupled model. The three density classes represent the upper and intermediate water mass (UW), deep water mass (DW) and bottom water

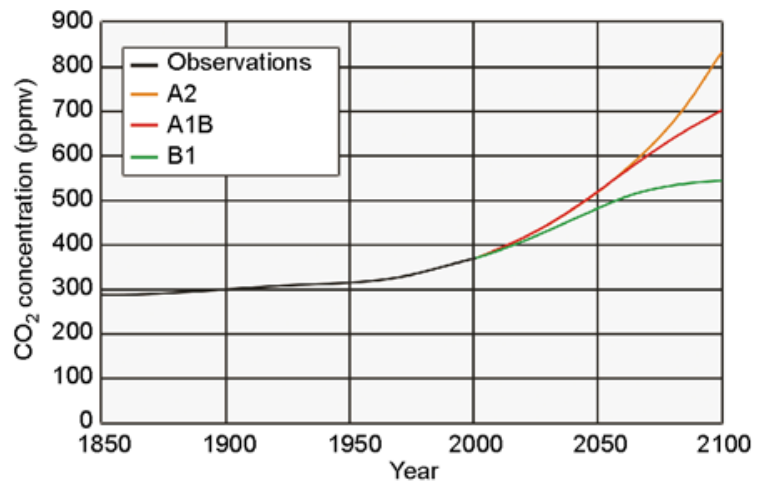

Figure $2 \mathrm{CO}_{2}$ concentrations of scenarios given in the IPCC evaluation report. mass (BW) in the Atlantic Ocean. The UW generally flows northward, while DW and BW flow southward in the North Atlantic. Under global warming due to increased concentrations of atmospheric $\mathrm{CO}_{2}$, the density structure of the ocean will change. In this work, a method is established to calculate the density criteria for classifying the different water masses (Figure 3), which change with global warming. We study a latitude of $50^{\circ} \mathrm{N}$ in the Atlantic because the strength of $\mathrm{THC}$ at $50^{\circ} \mathrm{N}$ is maximal. Along this section, we transform the meridional velocity field into a density coordinate. The potential density of seawater is calculated from the model output with a reference depth of $2000 \mathrm{~m}$. The meridional transport across the section from the surface down is then added to each density layer. The maximal northwardtransport density coordinate is $\sigma_{1}$, and the zero meridional transport density coordinate larger than $\sigma_{1}$ is $\sigma_{2}$. We define UW as seawater whose density is less than $\sigma_{1}$, DW as seawater whose density is between $\sigma_{1}$ and $\sigma_{2}$, and BW as seawater whose density is density greater than $\sigma_{2}$. We thus obtain the density criteria of different water masses under the scenario of a higher concentration of atmospheric $\mathrm{CO}_{2}$.

The upper ocean, which absorbs more radiation energy, warms more quickly than the deeper ocean. The potential density of UW decreases quickly under global warming, from 1036.72 to 1036.28 under the A1B scenario. Meanwhile, the potential densities of DW and BW do not fall as quickly as that of UW.

\section{Mechanism of the Greenland-Scotland Ridge overflow under the scenario of a constant concentration of atmospheric $\mathrm{CO}_{2}$}

\subsection{Mechanism of the strength of overflows}

Employing the method given by Whitehead [7], the model has two layers and the strength of overflow is calculated using formula (1).

$$
Q=\frac{1}{2} g \frac{\Delta \rho}{\rho} \frac{H_{\mathrm{eff}}^{2}}{f},
$$

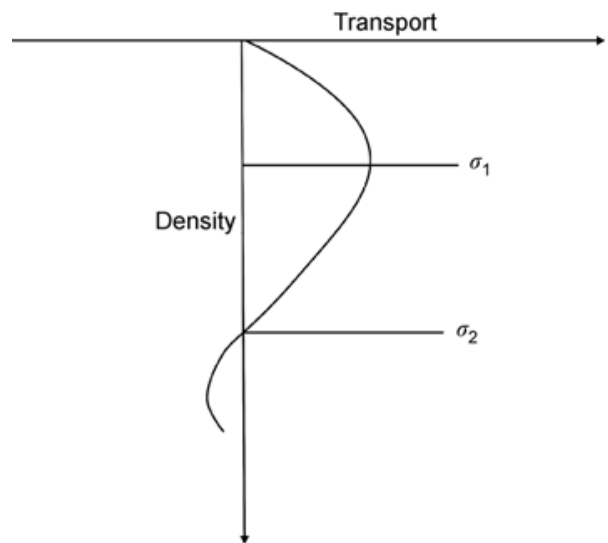

Figure 3 Density criteria for defining different density domains. 
Here $Q$ is the volume transport, $g$ is the gravitational acceleration, $\rho$ is the density, $\Delta \rho=\rho\left(T_{1}, S_{1}\right)-\rho\left(T_{2}, S_{2}\right)$ is the density difference across the ridge, $H_{\text {eff }}$ is the effective dynamic height in the two-layer model, and $f$ is the Coriolis constant. In addition, we obtain the strength of the overflow directly by calculating the net volume transport of DW and BW across the Denmark Strait and the Faro-Bank Channel.

To display changes in variables more clearly, the data on the strength of the overflow are normalized. The definition of normalization used here is (value of variable - average value of variable)/variance. The strength of the overflow calculated directly (black line) and that deduced from the baroclinic effect (red line) are shown in Figure 4(a) (Denmark Strait) and Figure 4(b) (Faro-Bank Channel). The results have good synchronism for both the Denmark Strait and the Faro-Bank Channel; the correlation coefficients are as high as 0.59 and 0.51 respectively (exceeding the $95 \%$ level of confidence). This demonstrates the importance of the baroclinic effect on the strength of overflow.

The strength of overflow is also compared with the strength of inflows crossing the Faro-Bank Channel in Figure 5(a) (Denmark Strait) and Figure 5(b) (Faro-Bank Channel). The strength of the inflow crossing the Faro-Bank Channel represents the total flux into the GIN Seas and the strength of barotropic outflow from the GIN Seas. Figure 5 shows that the overflows and inflows are in good agreement; the correlation coefficients are as high as 0.49 and 0.50 respectively (exceeding the $95 \%$ level of confidence). This indicates that the barotropic outflow is also closely related to the strength of overflow.

Figure 6 presents the evolution of the normalized averaged mixed layer depth of the GIN Seas (black line) and normalized inflow strength of the Faro-Bank Channel (red line). The depth of the mixed layer is an important physical element that denotes the stability of oceanic stratification. We define the mixed-layer depth over the GIN Seas as being from the sea surface to the depth where the density is one-eighth of the surface density. The averaged mixed-layer depth for the GIN Seas thus characterizes the stability of the stratification in the GIN Seas. Figure 6 shows that there is high correlation between the averaged mixed-layer depth of the GIN seas and inflow to the Faro-Bank Channel (the correlation coefficient is 0.48 , which exceeds the $95 \%$ level of confidence). These findings suggest that the stability of stratification in the GIN Seas is closely related to the strength of overflow.

We see from the discussion above that the strength of overflow is jointly controlled by the barotropic effect and
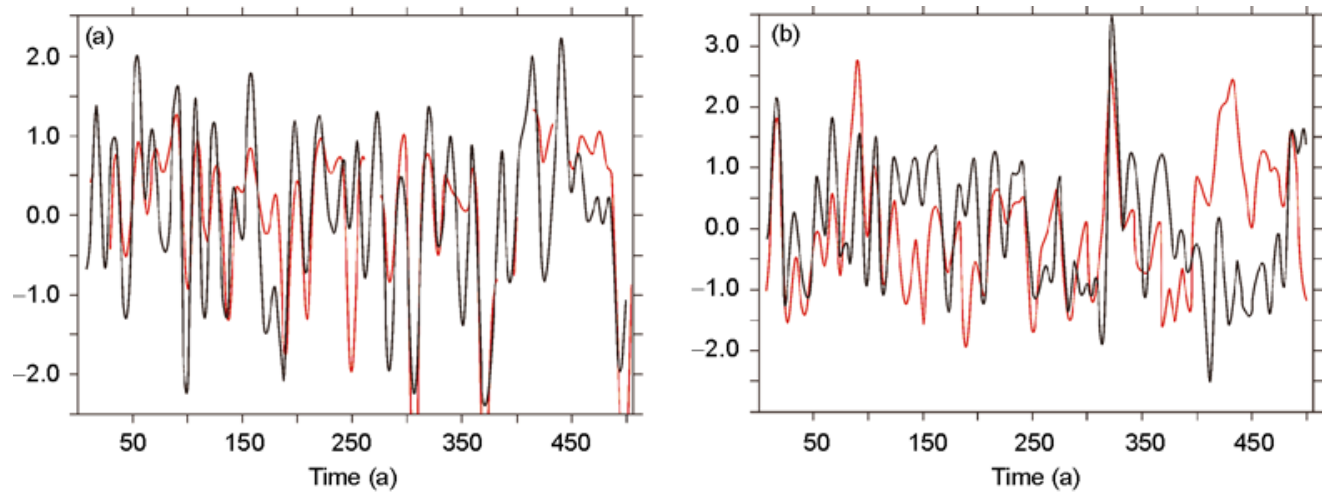

Figure 4 Time series of the strength of the overflow calculated directly (black line) and from the baroclinic effect (red line) for the Denmark Strait (a) and the Faro-Bank Channel (b). Values have been normalized.
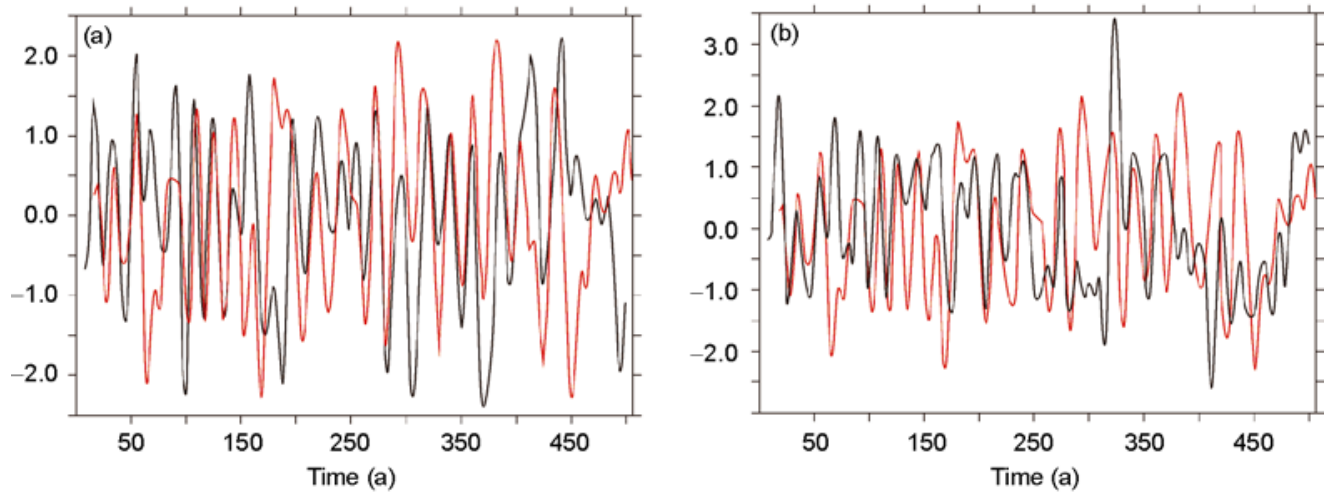

Figure 5 Time series of the strength of the Faro-Bank Channel inflow (red line) is compared with the strength of the overflow (black line) in the Denmark Strait (a) and the Faro-Bank Channel (b). Values have been normalized. 


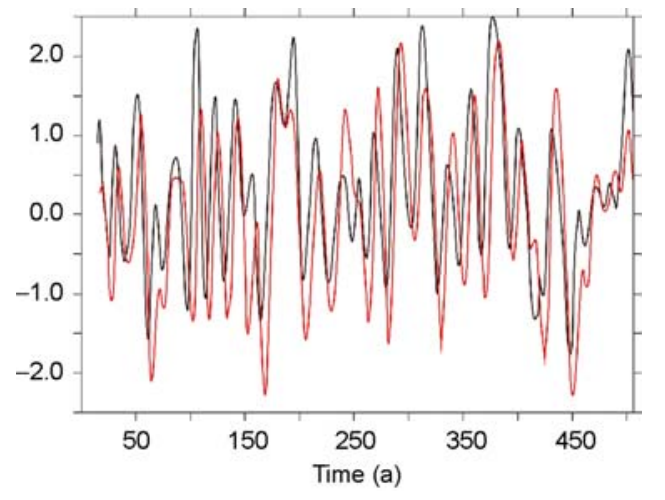

Figure 6 Time series of the stability of stratification in the GIN Seas, showing the averaged mixed-layer depth (black line) and the strength of the Faro-Bank Channel inflow (red line). Values have been normalized.

baroclinic effect; more water with higher salinity intruding into the GIN Seas brings about higher sea-surface density in the GIN Seas. This weakens the stability of water stratification and increases the probability of occurrence of deep convection, resulting in upwarped isotherms, increased deep-water density, greater density difference across the ridge and a higher effective dynamic height. Finally, the overflow strengthens under the baroclinic effect. Meanwhile, the inflow of water strengthens the cyclonic circulation in the GIN Seas and results in greater overflows under the barotropic effect. Therefore, the barotropic effect and baroclinic effect on the overflow are unified. This, the classical theory on overflow and the theory of Mauritzen [8,9] are only explanations of the same mechanism from different viewpoints.

\subsection{Relationship between the average density and the strength of the Greenland-Scotland Ridge overflow}

Figure 7 shows the time-dependent variation in the strength (black line) and average density (red line) of the overflow after normalization from model simulation. There is good synchronism between the strength and average density in the model; the correlation coefficients are as high as 0.42 and 0.45 respectively (exceeding the $95 \%$ level of confi- dence), suggesting that the strength and density of the overflow are closely correlated and synchronized. This is because of the fact that, as the overflow increases, the stability of stratification weakens, the deep convection in GIN Seas strengthens, isotherms upwarp and the deep-water density increases. Therefore, with an increase in overflow under the baroclinic effect, the density of the overflow increases, and we conclude that changes in the magnitude and density of overflow are highly synchronous.

\section{Mechanism of the Greenland-Scotland Ridge overflow under global warming}

\subsection{Mechanism of the overflow}

Using the analytical method described in section 1 for the result of the coupled climate models (Figure 8), it is found that the rate of generation of NADW is about $16.2 \mathrm{~Sv}$ in the 20th century, of which $8.2 \mathrm{~Sv}$ is from deep convection in the Labrador Sea, 5.9 Sv is from the overflow across the Denmark Strait and the Faro-Bank Channel, and 2.1 Sv is from entrainment in the south of the Denmark Strait Region. In the 21 st century under the A1B scenario of global warming, the values decrease to $12.9,5.2,6.1$ and $1.6 \mathrm{~Sv}$ respectively [16].

According to the discussion in section 2, the strength of strait overflow should be determined by the density difference across the ridge and the effective dynamic height. The time-dependent curve of density across the Denmark Strait (Figure 9(a)) and the Faro-Bank Channel (Figure 9(b)) indicates that the density has a significant decreasing trend under the A1B scenario.

Global warming under an increase in the concentration of atmospheric $\mathrm{CO}_{2}$ greatly affects the temperature of the global oceans, especially the Arctic and GIN Seas. For this reason, the density decrease on the northern side of the sea ridge is clearer than that on the southern side. This change could change the status of small density differences across the Greenland-Scotland Ridge. As a result of the strengthening of deep convection and upwarping of isotherms of
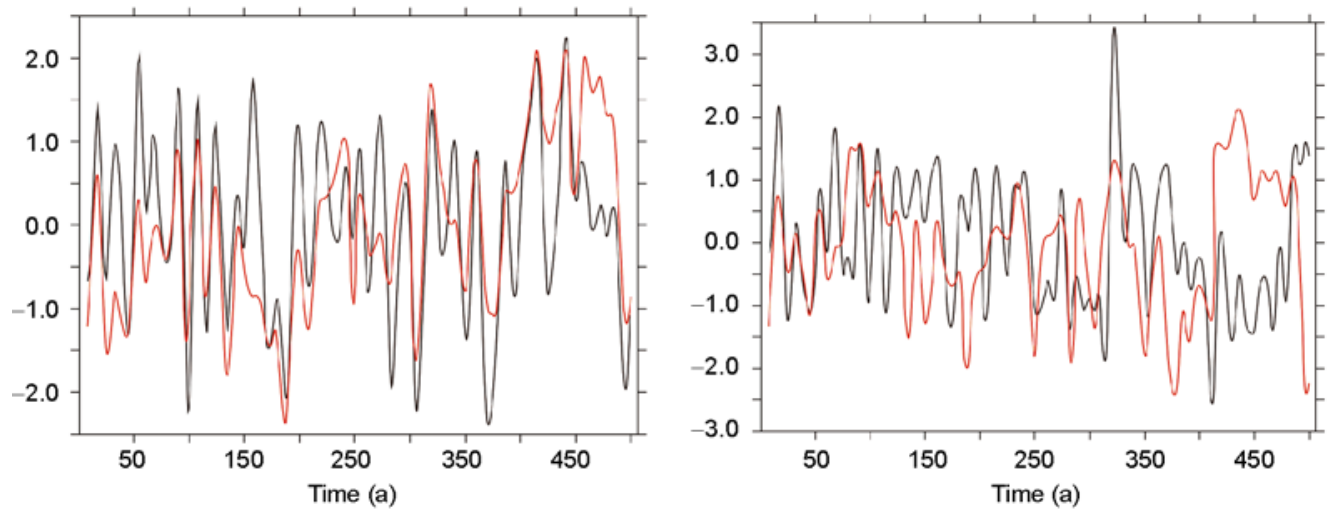

Figure 7 Variation in the strength (black line) and average density (red line) of the overflow after normalization according to model simulation. 

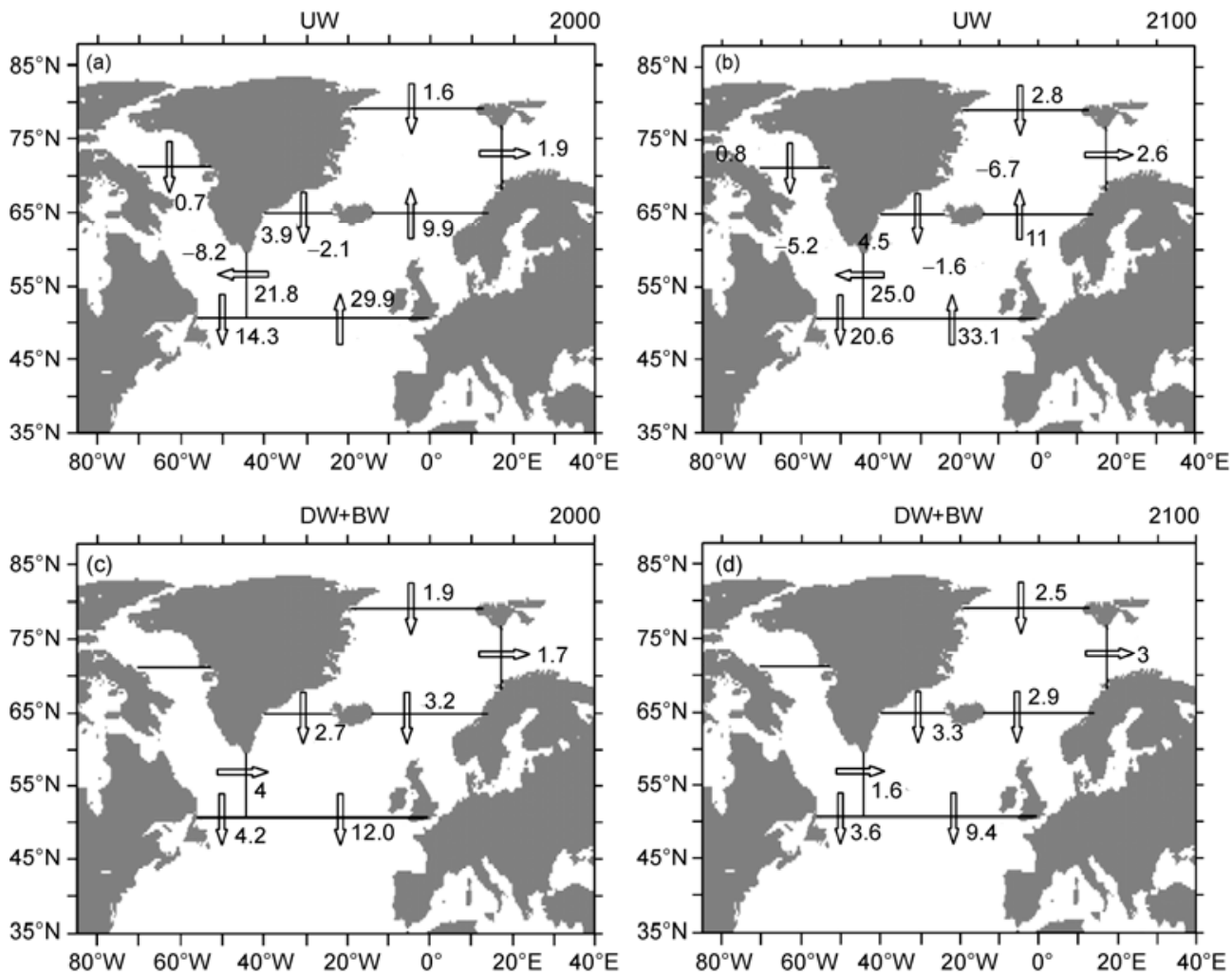

Figure 8 Isopycnal and diapycnal fluxes (Sv) under the A1B scenario. UW (top) represents the upper branch of the THC while DW+BW (bottom) represents the lower branch of the THC. (a) and (c) are for the 20th century; (b) and (d) are for the 21st century. Arrows indicate the direction of the isopycnal flow, while the numbers next to the arrows give the magnitude of isopycnal flow. The numbers at the centers of boxes give the strengths of diapycnal flux. A negative number means lighter water is converted into denser water.
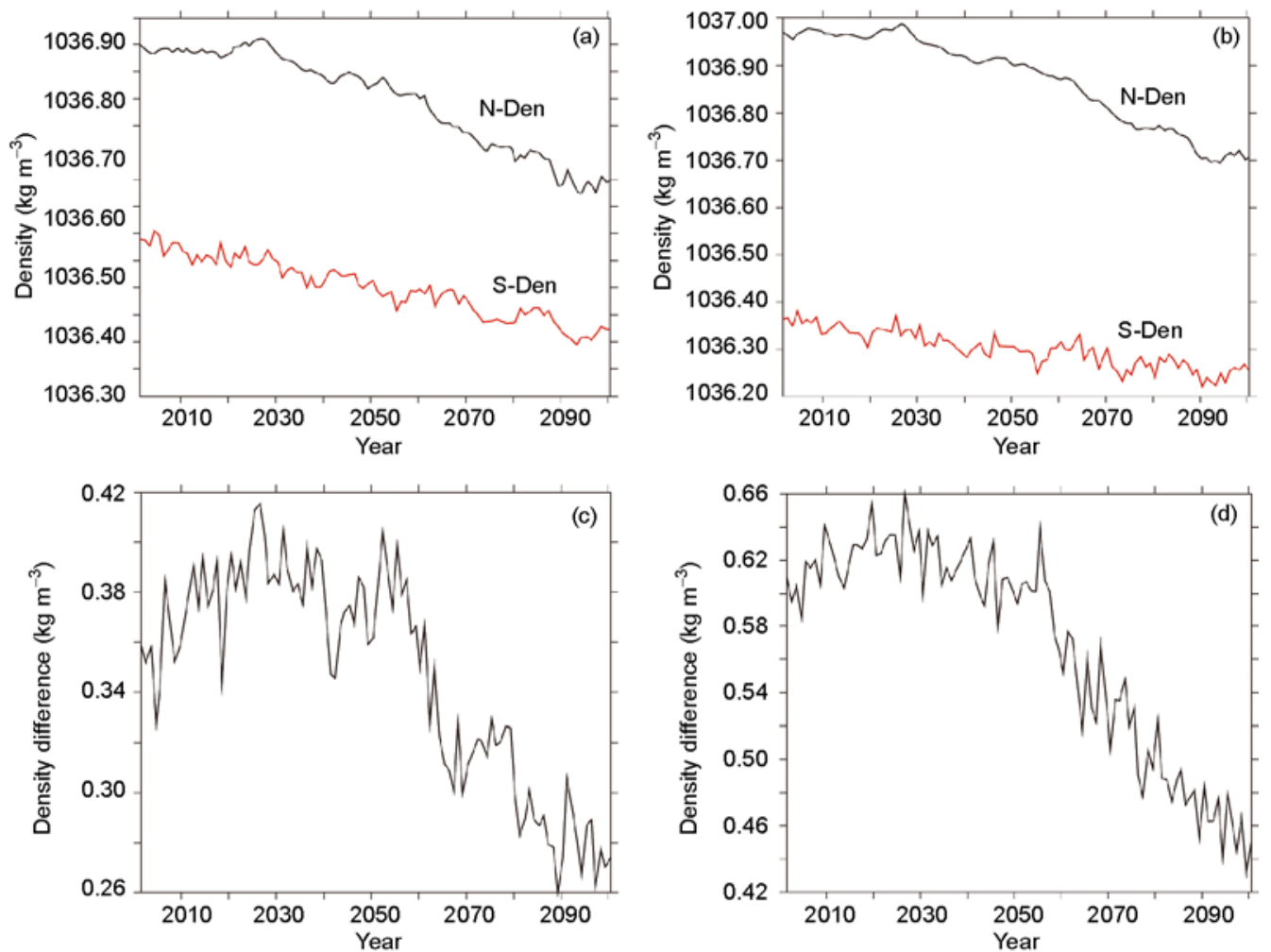

Figure 9 Time series of the overflow density $\left(\mathrm{kg} / \mathrm{m}^{3}\right.$ ) on the southern side (red line) and northern side (black line) for the Denmark Strait (a) and the Faro-Bank Channel (b) in the case of the A1B scenario. (c) and (d) show the density difference relevant to (a) and (b). 
GIN Seas, the effective dynamic height in the Denmark Strait and the Faro-Bank Channel will increase accordingly (Figure 10).

The time series of the strength of overflow in the Denmark Strait and the Faro-Bank Channel (Figure 11), which is generated by the baroclinic effect, shows that the decrease in density difference across the Greenland-Scotland Ridge plays a more dominant role than the effective dynamic height in controlling the overflow, and the overflow remarkably weakens under the A1B scenario. The overflow flux of the Faro-Bank Channel decreases from 3.2 to $2.9 \mathrm{~Sv}$ under the A1B scenario and it is in accordance with changes in the strength of overflow under the baroclinic effect. Meanwhile, Figure 8 shows that inflow across the FaroBank Channel increases significantly from 9.9 to $11 \mathrm{~Sv}$, and the cyclonic circulation in the GIN Seas and the overflow in the GIN Seas under the barotropic effect are strengthened (total outflow increases from 3.9 to $4.5 \mathrm{~Sv}$ for the Denmark Strait). This indicates that the strength of overflow across the Faro-Bank Channel is controlled by the baroclinic effect under the A1B scenario. On the other hand, the overflow flux for the Denmark Strait increases from 2.7 Sv (Figure $8(\mathrm{c})$ ) to $3.3 \mathrm{~Sv}$ (Figure $8(\mathrm{~d})$ ). This is a trend contrary to the changes in the strength of overflow under the baroclinic effect but the same as changes in the outflow under the barotropic effect

Figure 12 shows the cyclonic circulation in the GIN Seas, which is strengthened for both the UW and DW+BW. More inflow flux crossing the Faro-Bank Channel increases the outflow flux into the Barents Sea. Meanwhile, the strengthening of inflow into the Faro-Bank Channel is seen for all three classes of the UW and DW+BW. This indicates clearly that the enhancement of the outflow flux from the Denmark Strait is a result of the barotropic effect under the A1B scenario.

\subsection{Relationship between THC and the Greenland- Scotland Ridge overflow}

For a certain concentration of $\mathrm{CO}_{2}$, it is difficult to distinguish whether the main factor affecting THC is the strength or density of the overflow, which was discussed in section 2.2. However, against the background of an increased level of $\mathrm{CO}_{2}$ and global warming, the density of the overflow becomes the leading factor affecting the THC strength instead of the strength of the overflow.

Under the A1B scenario during the 21 st century, the strength of overflow increases from 5.9 to $6.2 \mathrm{~Sv}$, while the strength of THC decreases from 23 to $18 \mathrm{~Sv}$ [16]; i.e. the trends are opposing. This shows that the strength of the overflow is not the major factor affecting the strength of the THC. Figure 13 shows that the decreasing trend of the overflow density was similar to that of the THC density. This illustrates that the overflow density becomes the main factor

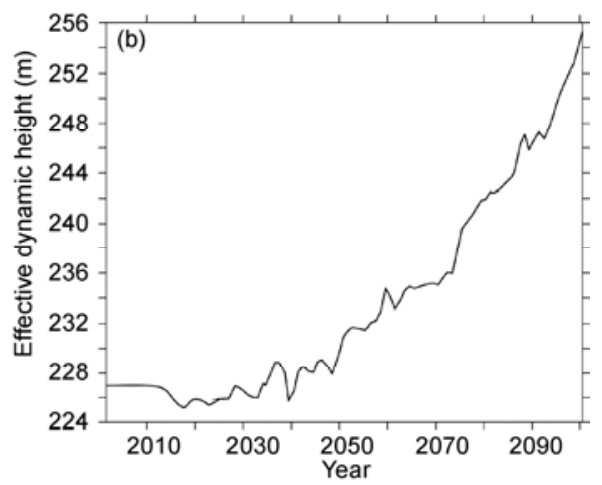

Figure 10 Time series of the effective dynamic height in the Denmark Strait (a) and the Faro-Bank Channel (b) in the case of the A1B scenario. The data were processed with 20 -year moving-average filters.
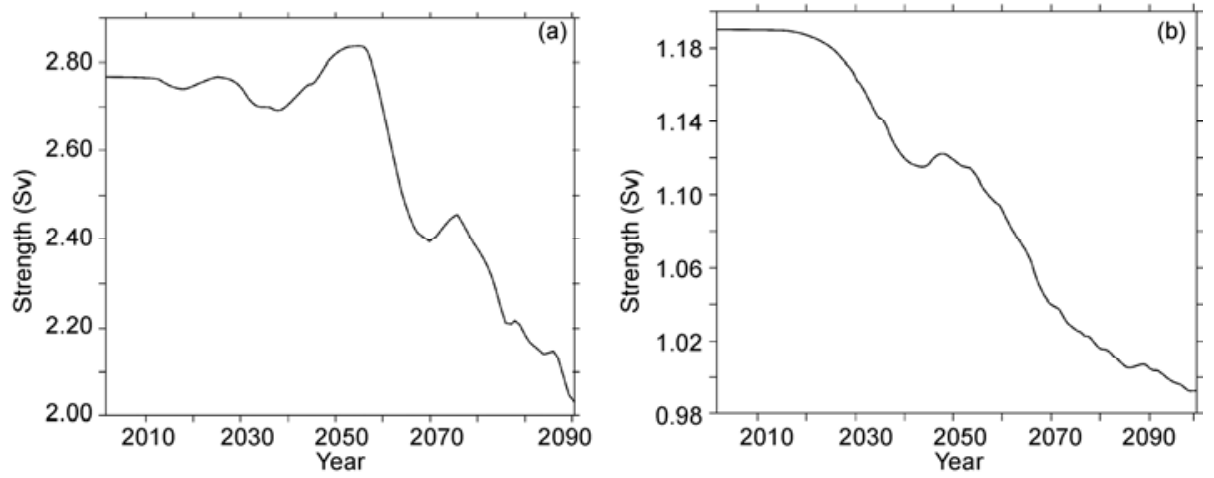

Figure 11 Time series of the strength of the overflow, generated by the baroclinic effect, in the Denmark Strait (a) and the Faro-Bank Channel (b). 


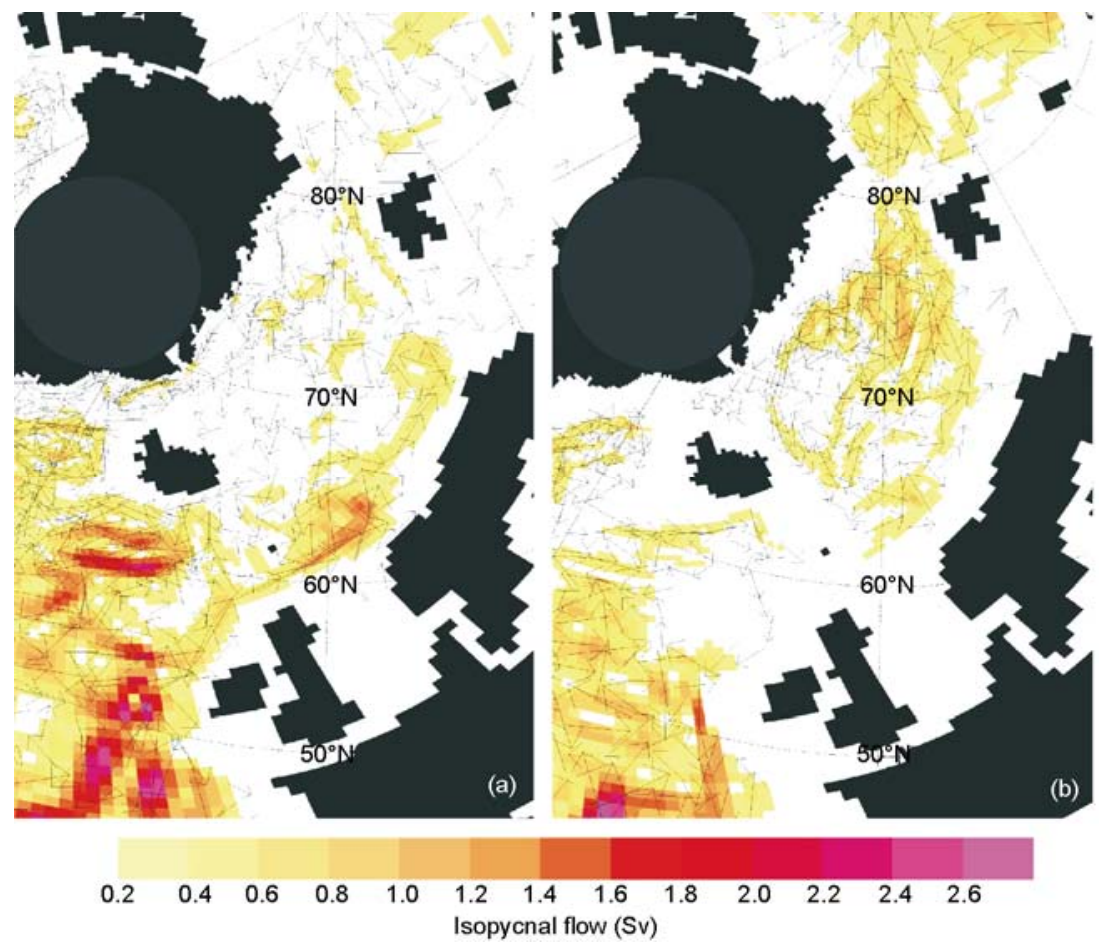

Figure 12 The difference in isopycnal flow (Sv) in the GIN Seas between the year 2100 and the year 2000 in the UW (a) and DW+BW (b). The arrows represent the transport direction and the color the strength.
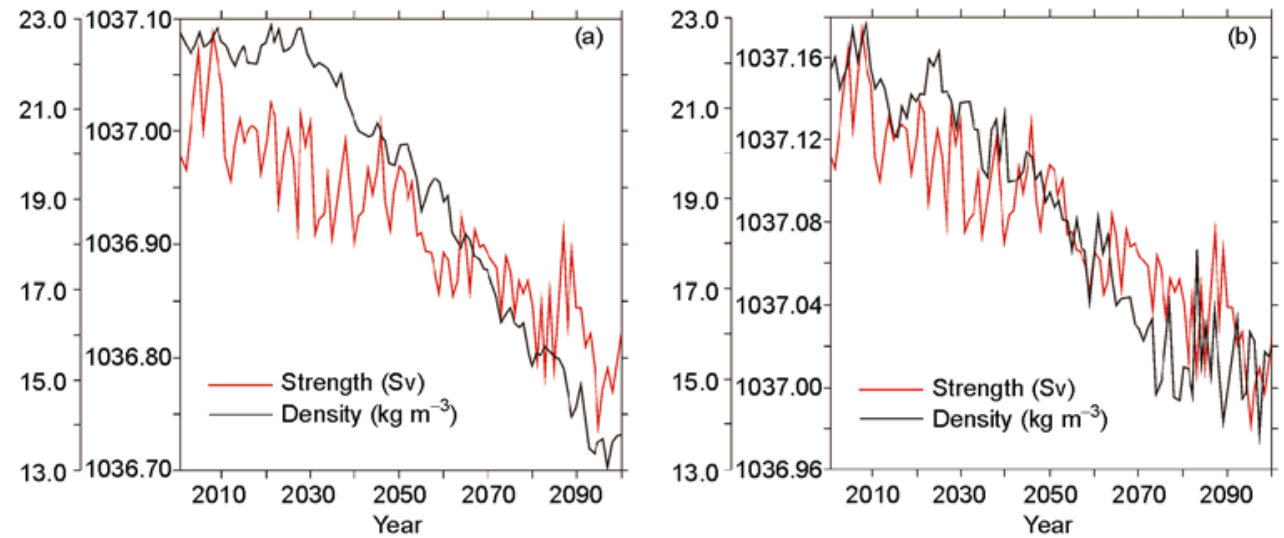

Figure 13 Time series of the overflow density (black line, $\mathrm{kg} / \mathrm{m}^{3}$ ) and the strength of THC (red line, Sv) in the Denmark Strait (a) and the Faro-Bank Channel (b) in the case of the A1B scenario.

affecting the strength of the THC.

The variation in the overflow density changes the structure of the density field in the Labrador Sea. The strength of density current in deep layers is thus affected, and it further influences the Deep Western Boundary Current (DWBC). Consequently, the density of the overflow becomes the major factor affecting the strength of the THC.

As shown in Figure 14, under the A1B scenario, there is a particular meridional density distribution in the $52^{\circ} \mathrm{W}$ section of the Labrador Sea in the year 2000, the structure of which is high at both ends and low in the middle. This is due to the density of DWBC, which is an extension of the overflow, being higher than the density of the Labrador Sea, thereby strengthening the pressure gradient directed toward the center of the Labrador Sea.

According to the geostrophic relationship, the cyclonic circulation strengthens in the Labrador Sea. As global warming in 2100 will change sharply in the areas of the GIN Seas and the Arctic, the overflow density will greatly decrease and become equivalent to or even lower than the seawater density in the Labrador Sea. For this reason, the variation in the pressure gradient directed toward the center of the Labrador Sea will reduce. Because of the influence of the Coriolis force, the variation in the pressure gradient will weaken the cyclonic circulation and the DWBC in the Labrador Sea, while the THC will weaken accordingly. 

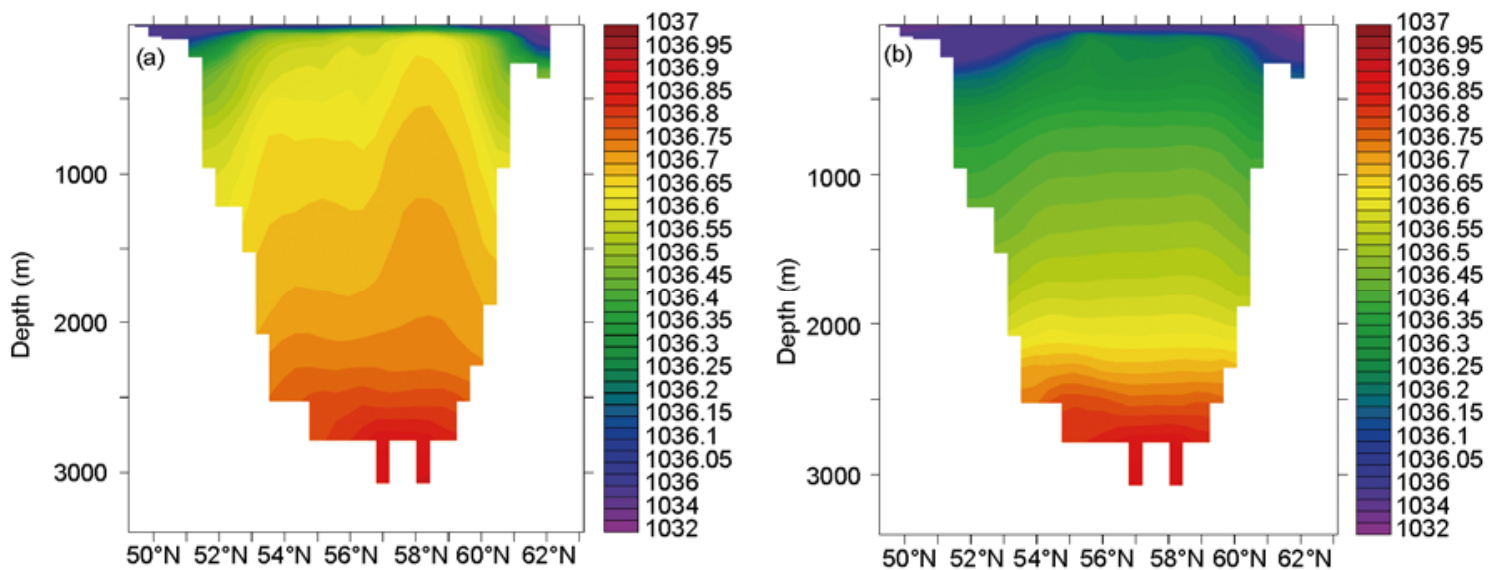

Figure 14 Density $\left(\mathrm{kg} / \mathrm{m}^{3}\right)$ profile along the section of $52^{\circ} \mathrm{W}$ in the Labrador Sea in the years 2000 (a) and 2100 (b) with latitude and depth (m).

\section{Conclusions}

The mechanism of the Greenland-Scotland Ridge overflow response to different scenarios of atmospheric $\mathrm{CO}_{2}$ levels was discussed, employing the Max Planck Institute's model, ECHAM5/MPI-OM, an newly developed advanced climate Atlantic ocean-atmosphere coupled model. The following conclusions were drawn.

(1) In the $\mathrm{CO}_{2}$ scenario before industrialization, more water with higher salinity intruding into the GIN Seas results in a higher sea surface density of the GIN Seas. This weakens the stability of water stratification and increases the probability of occurrence of deep convection, resulting in upwarped isotherms, higher deep-water density, a high density difference across the ridges and high effective dynamic height. The overflow thus strengthens under the baroclinic effect. Meanwhile, the intruding water strengthens the cyclonic circulation in the GIN Seas and increases the overflow under the barotropic effect. Therefore, the barotropic effect and baroclinic effect are unified for the overflow.

(2) A coupled model was run under different scenarios of higher concentrations of atmospheric $\mathrm{CO}_{2}$, which are listed in the IPCC report. Under the A1B scenario, the strength of overflow across the Faro-Bank Channel is controlled by the baroclinic effect and the increase of Denmark Strait overflow is attributed to the barotropic effect. The density, not the strength, of the overflow becomes the main factor affecting the strength of the THC under global warming.

The first author wishes to thank Dr J. H. Jungclaus and Dr H. Haak for their help and comments while studying at the Max-Planck Institute as a Ph.D. student. This work was supported by the National Natural Science Foundation of China (40940025 and 41006002), the Public science and technology research funds projects of ocean (200905001, 201005019 and 2012418018), the Tianjin Municipal Science and Technology Commission project (09JCYBJC07400), and DAAD fund.
1 Schmitz W J. On the interbasin-scale thermohaline circulation. Rev Geophys, 1995, 33: 151-173

2 Broecker W S. The great ocean conveyor. Oceanography, 1991, 4: 79-89

3 Zhou T J, Wang S W. Preliminary evaluation on the decadal scale variability of the North Atlantic Thermohaline Circulation during 20th century (in Chinese). Clim Environ Res, 2001, 6: 294-304

4 Manabe S, Stouffer R J, Spelman M J. Transient response of a coupled ocean-atmosphere model to gradual changes of atmospheric $\mathrm{CO}_{2}$, Part I: Annual mean response. J Clim, 1991, 4: 785-818

5 Swift J H, Aagaard K, Malmberg S A. The contribution of the Denmark Strait overflow to the deep North Atlantic. Deep Sea Research Part A. Oceanogr Res Papers, 1980, 27: 29-42

6 Mccartney M S, Talley L D. Warm-to-cold water conversion in the northern North Atlantic Ocean. J Phys Oceanogr, 1984, 14: 922-935

7 Whitehead J A. Topographic control of oceanic flows in deep passages and straits. Rev Geophys, 1998, 36: 423-440

8 Mauritzen C. Production of dense overflow waters feeding the North Atlantic across the Greenland-Scotland Ridge. Part 1: Evidence for a revised circulation scheme. Deep-Sea Res, 1996, 43: 769-806

9 Mauritzen C. Production of dense overflow waters feeding the North Atlantic across the Greenland-Scotland Ridge. Part 2: An inverse model. Deep-Sea Res I, 1996, 43: 807-835

10 Arne B, Rolf H K, Detlef B S. The sensitivity of the GreenlandScotland Ridge overflow to forcing changes. J Phys Oceanogr, 2003, 33: 2307-2319

11 Jungclaus J H, Macrander A, Kase R. Modelling the overflows across the Greenland-Scotland Ridge. In: Dickson B, Meincke J, Rhines P. Arctic-subarctic ocean fluxes: Defining the Role of the Northern Seas in Climate. Heidelberg: Springer-Verlag Press, 2008

12 Iréne L, Peter L. Seasonal barotropic modulation of the Deep-Water Overflow through the Faroe Bank Channel. J Phys Oceanogr, 2006, 36: 2328-2339

13 Roeckner E, B Uml G, Bonaventura L, et al. The atmospheric general circulation model ECHAM5: part 1: Model description. Max-Planck Institut für Meteorologie-Report, 2003. 123-349

14 Marsland S J, Haak H, Jungclaus J H, et al. The Max-Planck-Institute global ocean/sea ice model with orthogonal curvilinear coordinates. Ocean Model, 2003, 5: 91-127

$15 \mathrm{Mu} \mathrm{L}, \mathrm{Wu} \mathrm{D}$, Chen X, et al. Analyses of the predicted changes of the global oceans under the increased greenhouse gases scenarios. Chinese Sci Bull, 2006, 51: 2651-2656

$16 \mathrm{Mu} \mathrm{L}, \mathrm{Wu} \mathrm{D}$, Chen X, et al. Changes of the Atlantic Thermohaline Circulation under the different atmospheric $\mathrm{CO}_{2}$ scenarios in a climate model. J Chin Univ Geosci, 2006, 17: 97-102

Open Access This article is distributed under the terms of the Creative Commons Attribution License which permits any use, distribution, and reproduction in any medium, provided the original author(s) and source are credited. 